\title{
Batılı Gezginlerin Gözlemlerinde Yörük/Türkmen Çadırları
}

\section{Yoruk/Turkman Tents in Observations of Western Travellers}

\author{
Mehmet $\mathrm{AK}^{1}$ (1)
}

'Sorumlu yazar/Corresponding author: Mehmet Ak (Doç. Dr.),

Alanya Alaaddin Keykubat Üniversitesi, Eğitim Fakültesi, Sosyal Bilgiler Eğitimi Anabilim Dalı, Alanya, Antalya, Türkiye

E-posta: mehmet.ak@alanya.edu.tr

ORCID: 0000-0002-0794-9046

Başvuru/Submitted: 08.09.2019 Revizyon Talebi/Revision Requested: 18.09.2019

Son Revizyon/Last Revision Received:

22.10.2019

Kabul/Accepted: 24.10 .2019

Online Yayın/Published Online: 13.11.2019

Atıf/Citation: Ak, Mehmet. "Batılı Gezginlerin Gözlemlerinde Yörük/Türkmen Çadırları." Türkiyat Mecmuası-Journal of Turkology 29, 2 (2019): 347-366.

https://doi.org/10.26650/iuturkiyat.646475 öz

Osmanlı Devletinin hâkim olduğu topraklar hemen hemen her dönem Batılı gezginlerin dikkatini çekti. Türk topraklarına çeşitli amaçlarla gelen gezginler, gezdikleri yerlerde gördükleri ve ilgilerini çeken birçok şeyi kaleme aldılar. Gezileri sırasında özellikle Türk toplumunun önemli unsurlarından birisi olan Yörük veya Türkmen olarak adlandırılan konargöçerler ile ilgili gözlemlerini de kayda geçirdiler. Bunların kışlak, yaylak ve güzlek arasında mevsim farkına bağlı olarak sürdürdükleri hareketli yapıları nedeni ile oturdukları çadırlar ve diğer mesken türlerini bazen ayrıntılı bir şekilde bazen de genel olarak ele aldılar. Çadırların donanım, kurulum ve iç mekân özelliklerine değindiler. Bu çadırlardan, karaçadır ismini sıkça verirlerken topak ev, alaçık, huğ ve diğer mesken türlerinin adlarından bahsetmediler ancak çoğunlukla şeklen tanıtıp çeşitli özellikleri veya genel görünümlerini betimlediler. Gözlemler sonucunda gezginler, var olan ortamı çoğu zaman olduğu gibi anlatmaya çalıştılar ancak romantik bir bakış açısı sergileyenler yanında zaman zaman oryantalist bakış açısından kurtulamayanlar da oldu. Gezginler, verdikleri bilgiler ile çadır türleri ve kullanılan meskenlerin çeşitliliğinden bahsedip bunların yöre ve bölge dağılımını ortaya koydukları gibi hem farklı çadır türlerinin, hem de çadırlar ile birlikte farklı meskenlerin aynı ortamda kullanıldığını gözler önüne serdiler.

Anahtar kelimeler: Yörük, Türkmen, Çadır, Yaylak, Gezgin

\section{ABSTRACT}

The lands of Ottoman domination have attracted Western Travellers in almost all periods of history. The travellers visiting Turkish lands with different purposes penned lots of things they saw and were attracted to. They also recorded their observations, especially about the konargoçers called Yoruk or Turkman, which were one of the essential elements of Turkish Society in their travels. They referred to their tents in use due to their mobile way of life, depending on the seasonal variations in winter quarters, pasture and fall range, and their other types of domicile, either in detail or in general. They also referred to the equipment, set up and interior characteristics of the tents. While they mentioned the name, karaçadır, they did not speak of topak ev, alaçık, huğ and the names of the other types of domicile, but mostly, they described their general appearance and forms. Based on their observations, these travellers mostly tried to describe the surrounding as it was. However, there were some who could not get rid of their Orientalist point of view, as 
well as others who put forward a romantic perspective. The travellers unfolded both the different types of tents, and several other types of domicile used together with them while they put forward their regional and geographical distribution by mentioning the varieties of dwellings and tent types in their information.

Keywords: Yoruk, Turkman, Tent, Pasture, Traveler

\section{EXTENDED ABSTRACT}

The Turkish Geography in Ottoman domination has attracted Western Travellers in almost all periods of history. The Western travellers penned several tangible objects and cultural heritage that attracted their attention. Within that period, they also recorded their observations, especially about the konargoçers called Yoruk or Turkman, which were one of the essential elements of Turkish Society in their travels. Their tents in use due to their mobile way of life, depending on the seasonal variations in winter quarters. pasture and fall range, and their other types of domicile were the first things which attracted their attention. Especially, tents were described in detail in terms of their appearance, equipment and set up besides their structures, and sometimes, they were mentioned in general. These travellers mostly tried to describe the surrounding as it was, but there were some who could not get rid of their Orientalist point of view, and described the surrounding according to their ideology, as well as others who could not hide their admiration with a romantic perspective.

The types of the tents the konargoçers used and the travellers mentioned in their observations are various, such as topak ev, karaçadır and alaçık. Besides these tents, there were also huğ, hovel and soil covered dwellings with stone-walls. It is also observed that topak ev and karaçadır, or topak ev and hovel were used together.

The name, topak ev, was not given directly in the travellers observations, but described in detail, and its qualities were mentioned. The topak ev resembled a cage, egg, bent basket, circular structure or hemisphere. There is also information about its wooden sections and felt cover. It was reflected that the topak ev was also covered with goat, black sheep and cow skins, as well as felt. It was said that it provided protection against cold weather, described as adverse weather conditions. While its appearance was described, its equipment, set up, transportation by rolling it up and forms of utilisation, were mentioned in detail. Several evaluations were made, and the price information about felt covers and wooden sections were given by referring to their height and width. The population harbouring in the topak ev was also mentioned. When the geographical distribution of this tent is reviewed by observing the travellers narrations, it is apparent that it was used in the Mediterranean, Aegean, Marmara and Central Anatolia Regions. Likewise, the topak ev stands out as a type of tent that was used together with the karaçadır in almost all of these regions.

It was pointed out that the Karaçadır was weaved with sheep wool, though goat hair was mostly used. The Karaçadır was often mentioned in the notes of the travellers. The interior and the exterior equipment, its sections and intended use were described, as well as 
its weaving, equipment, set up, and usage characteristics. The waterproofing of the karaçadır was mentioned, and it was said to be cooler when compared to the topak ev. Its number of posts, width and height were also given. The tent flaps, referred to as tent canvas, the guy ropes, the side and front cover styles and the nails used to attach the bonds, were mentioned. Information was given about the stone-wall and straw lay around the karaçadır. It was asserted in the notes and observations of the travellers that the karaçadır, which was used in different parts and regions of the Turkish geography, was weaved and prepared in several different shapes and sizes.

The travellers did not mention the alaçı as another tent type, but the tent type which the travellers wandering around Teke Region called as karaçadır, is actually the alaçık. However, it was not popular in other regions. This tent was only described by its appearance, and few details were given.

The type of dwelling which the travellers called as a cottage, without giving a specific name, and was built with the canes cut from places close to swamps and lakes is known as a huğ. This dwelling was surrounded by cane hedges, surrounded by long nails and covered with canes again on beams and poles. In this sense, the huğ was transported short distances although it was considered as a permanent dwelling. It was observed that the dwellings made of adobe, and covered with clay, were used by the konargoçers besides other dwellings said to be made of cane, without giving a specific name.

Besides the dwelling mentioned as a cave covered with a wall-like soil, the existence of the dwelling mentioned as a circular cottage draws attention. Also, the inspiration in building it was said to be topak ev. The structure which was used with the topak ev, came into prominence with its woodworking, and called a wooden cottage by the travellers.

Additionally, there were also dwellings covered with soil on stone-walls and flat roof, described as primitive when compared to the houses of the settled society. The tent weaved with camel hair, its qualities and interior equipment was described without mentioning its special name. 


\section{Giriş}

Osmanlı Devleti'nin sahip olduğu Türk coğrafyası Batılı gezginlerin hemen hemen her dönem ilgi odağı hâline geldi. Bu süreçte doğu dünyasının gizemine kapılan gezginler, gezdikleri yerlerde gördükleri her şey gibi Türk toplumunun mevsim farkına bağlı olarak yaylak, kışlak ve güzlek arasında konargöçer hayat yaşayan Yörük veya Türkmen olarak adlandırılan kısmı ile ilgili gözlemlerini de kayda geçirdiler. Özellikle bu konargöçer kitlenin oturdukları en önemli barınakları çadırlar ile diğer mesken türleri olup gezginlerin ilk dikkatini çeken hususlar içerisinde yer aldığı gibi bunları ya genel olarak ya da ayrıntılı bir şekilde tasvir ettiler.

Gezginlerin eserlerinde bahsettikleri çadırlar, taşıma, kurulum ve kullanım kolaylığına sahip önemli birer sanat eseri olup bunların dokuma kısmını kadınlar, ağaç aksamını erkekler yaptıkları gibi çadır ve donanımını dokuyup çeşitli keçe türlerini döken kadın iken bakaraları, direkleri, çivileri, çöpleri ve topak evin ahşap aksamını yapan erkeklerdir.

\section{Topak Ev}

Yörük veya Türkmen olarak adlandırılan kitlenin kullandığı önemli konutlardan birisi topak ev, derim ev ve bekdik çadırı da denilen ahşap aksam üzerine keçe örtülerek yapılan kümbet şeklindeki çadırdır. ${ }^{1}$ Batılı gezginler, Türk topraklarında rastladıkları bu çadır türünden bahsedip çeşitli özelliklerini belirttikleri gibi 1432 yılında Türkiye'nin güneyinde, Payas'ta, dağlar ile deniz arasında güzel insanlar olarak nitelendirilen Türkmenlerin yaşadığ 1 belirtilir. Bunların çadırlarını daima kırsal yerlerde kurdukları, bulundukları yerden başka bir yere giderken de keçelerle kaplanmış yuvarlak çadırlarını yanlarında götürdükleri dile getirilir. Yaklaşık yüz yirmi civarında olduğu belirtilen bu Türkmen çadırları, görülebilecek en güzel çadırlar olarak nitelendirilip beyaz pamuklu kumaş ve mavi keçeden yapıldıkları beyan edilir. Bu çadırlar, içerisinde on beş veya on altı kişi kalabilecek kadar büyük olup bir evde neler varsa, ateş hariç olmak üzere hepsi bu çadırların içinde mevcut şeklinde genel bir betimleme yapılır. ${ }^{2}$ Uzun yıllar sonra yine aynı çevrede Halep, Afrin ve Hatay Yöresi'nde yaşayan Reyhanlı Türkmenlerinin 1810 yılında, büyük beyaz yün keçelerle kaplı yuvarlak kuş kafesi gibi tahtadan yapılmış bir tür taşınabilen çadırlarından bahsedilir. Bu çadırın girişi küçük bir kapıyla kapatılabildiği gibi kadınların münhasır yaşam alanı olarak nitelendirilip yalnızca büyük mülkiyete sahip ailelerde bulunduğu belirtilir. ${ }^{3}$ Aynı şekilde Tarsus’taki Türkmenlerin bir arada topluca kurdukları çadırların, Yörük çadırlarından farklı olarak kalın keçe kumaşlarla kaplı kafes şeklinde olduğu ve en ağır hava koşullarına karşı koruma sağladığ 1 ifade edilir. ${ }^{4}$

1 Mehmet Ak, Teke Yörükleri (1800-1900) (Ankara: TTK Yayınları, 2015), 107.

2 Bertrandon De La Broquiere, Bertrandon De La Broquiere'in Denizaşırı Seyahati, çev. İlhan Arda, (İstanbul: Eren Yayınlar1, 2000), 168, 170.

3 John Lewis Burckhardt, Travels in Syria and the Holy Land (London: Published by the Association for Promoting the Discovery of the Interior Parts of Africa, 1822), 636.

4 E. J. Davis, Life in Asiatic Turkey, a Journal of Travel in Cilicia, (Pedias and Trach(ea) Isauria, and Parts of Lycaonia and Cappadocia (London: Printed by Edward Stanford, 1879), 201. 
Aydın Yöresi’nde Güzelhisar'a giderken Okluk köyü yanında büyük bir Türkmen obası gören Arundell, bu Türkmenlere ait her zamanki karaçadırların yanı sıra dairesel bir şekle sahip başka çadırlar da olduğunu dile getirir. Bu Türkmenlerden bazılarının o zamanlar, çok ustaca ve ferah bir şeklide bu çadırları yaptıklarını belirtir. Kurulumunda ise bir kaburga çerçevesinin sıkıca birbirine birleştirildiği ve sıkıca gerilmiş çadır bezi ile tamamen kaplandığı kaydedilirken yörede karaçadırların yanında topak evin de varlığı ve kullanıldığı görülür. Yine Dombay Ovası'nın girişinde Türkmenlerin çadırları ovanın büyük bir bölümünü kaplar. Bu çadırlar, yuvarlak yapısı ile yerden bir buçuk veya iki metre yüksekliğinde, kalın hazırlanmış saz bitkisinden kurulur. Üstü açık kafes şeklinde olup çit örgü ile yapıldığı gibi bezle alçak bir kubbe olarak örtüldüğü belirtilir. ${ }^{5} \mathrm{Bu}$ tür düşük yuvarlak kubbe şeklindeki çadırları, İzmir yakınlarındaki Yörükler ile iç kısımlardaki bazı Türkmenlerin kullandıkları dile getirilir. ${ }^{6}$ Ayrıca 19. yüzyılın ilk yarısında Uludağ' da yaşayan ve Texier'in deyimi ile Yörük denilen konargöçer Türkmenlerin yaylada kurdukları iki tür çadırdan bahsedilir. Bunlardan birisi ahşaptan yapılan, yuvarlak ve üzeri kubbe şeklindeki bir tavanla kapatılan, örtüsü keçi veya inek derisinden mamul çadır olarak anlatılır. Çitlerinin katlanır ve dürülür kamış perdelerden yapıldığı ve taşınmalarının güç olduğu belirtilirken ${ }^{7}$ bu yörede topak evin dış kısmına keçe yerine keçi veya inek derisi örtüldüğü anlaşıldığı gibi benzer şekilde Aydın Güzelhisar yakınlarında karakoyun derisinden yapılmış Türkmen çadırlarından bahsedilir. ${ }^{8}$

Çanakkale Yöresi'nde Evciler ve Bayramiç yakınlarında yaz aylarında Türkmenlerin kurdukları çadırlar, dairesel biçimde ve üstte bir açıklığın bulunduğu yuvarlak yapısı ile dışı keçe kaplı kafes şekline benzetilir. Bu çadırların içerisinin halı ve minderlerle döşeli olduğu belirtilirken böylece iç ve dış donanımı hakkında önemli bilgiler verilir. Bu bilgiler yanında gezgin Tozer, bu çadırları daha önce gördüklerinin aksine tüm özellikleri ile Kalmuk Tatarlarının çadırlarına benzetir. ${ }^{9}$ Yine başka bir gezgin Lennep, Anadolu Türkmenlerinin, Tatarların kullandıkları çadırlara benzeyen aynı tür çadırlar altında yaşadıklarını ancak bu çadırların, Batı Anadolu'da yaşayan diğer konargöçerlerin çadırlarına benzemediğini dile getirir. Bunların çadırlarının yaklaşık dört metre çapında dairesel bir yapıda olduğu ve yere sıkıca bağlandığı, bir dairede ikiye bölünmüş, merkeze doğru bükülmüş ve üstte ortada birleştirilmiş bir dizi uzun esnek dallar ile kurulduğu beyan edilir. Bu şekilde iskeleti kurulduktan sonra bu çerçeveye akıntı verecek şekilde geniş keçe parçalarının örtüldüğü

5 Fr. V. J. Arundell, A Visit to the Seven Churches of Asia; With Excursion into Psidia; Containing Remarks on the Geography and Antiquities of Those Countries (London: Published by John Rodwell, 1828), 60, 246.

6 William J. Hamilton, Researches in Asia Minor, Pontus, and Armenia; with Some Account of Their Antiquities and Geology, (London: Printed by William Clowes and Sons, 1842), I: 385.

7 Charles Texier, Küçük Asya Coğrafyası Tarihi ve Arkeolojisi, çev. Ali Suat (Ankara: Enformasyon ve Dökümantasyon Hizmetleri Vakfı Yayını, 2002), 1: 231.

8 F. A. De Chateaubriand, Itineraire de Paris a Jerusalem et de Jerusalem a Paris, (Paris: Le Normant, İmprimeur-Libraire, 1812), II: 34.

9 Henry Fanshawe Tozer, Researches in the Highlands of Turkey Including Visit to Mounts Ida, Athos, Olympus, and Pelion, to the Mirdite Albanians, and Other Remote Tribes, (London: Printed by William Clowes and Sons, 1869), I: 19. 
ve çadırın böylece yarım kürenin şeklini aldığı, yüksekliğinin insan boyundan biraz fazla olduğu belirtilir. ${ }^{10}$

Sakarya Irmağı havzasında Öyük ile Bağlıca arasında yaşayan Türkmenlerin çadırları, üstte yuvarlanmış ve hafif bükülmüş çubuk çerçevesi üzerine yayılmış keçe parçaları ile örtülü şekilde betimlenir. Çadırın rüzgâr ve güneş gelen tarafının örtüsünün yükseltilip açıklığın, Türk haremlerinin pencerelerinde kullanılan kafesler tarafından tutulduğu belirtilir. Bununla birlikte bu açıklığın en alçak kısmı, güneş 1şınlarının ısısının zeminden çadırın içine yansımasını önleyen birkaç ayak yüksekliğinde bir tahta veya bezle kapatıldığı dile getirilir. ${ }^{11}$ Kütahya hattında Kümbet köyünden sonra Perrot ve Chipiez tarafından yol üzerinde rastladıkları Yörüklerin yaz aylarında oturdukları meskenlerden birisi keçeden yapılmış yumurta şeklindeki çadırlar olarak betimlenir. ${ }^{12}$ Ankara yakınlarındaki Türkmenlerin çadırları bir çan şeklinde, üç metre çapında ve ortada aynı yükseklikte, duvarın alt kısmı kamışlardan yapılmış hasırlardan oluşurken hava ve 1şı̆̆ın hasırın ortasından içeriye girdiği ve kafes şeklindeki yapının üzerine çatıya keçe örtüldüğü ifade edilir. Hafif ve kolay taşındığ 1 belirtilen bu çadırların bir bütün olarak kumaştan yapılandan daha serin ve rahat oldukları hatta obanın ortasında daha büyük boyutlardaki bu tür bir çadırın genellikle yabancıların kabulü için bir tür halka açık salon olarak kurulduğu beyan edilir ki ${ }^{13}$ bu durum konargöçer kültüründe konuk ağırlama bakımından önemli bir husustur.

Gezginlerden topak ev ile ilgili ayrıntılı betimlemeler yapanlar da olup Ereğli yakınlarındaki Türkmen çadırları yuvarlak keçe kaplı şekilde tarif edilir. Bu çadırları inceleyen gezgin Davis, onları çok elverişli bulur ancak tarif etmenin zor olduğunu belirtirse de ayrıntılarından bahseder. Çadırın iskeleti ve kurulum ile ilgili verilen bilgiye göre çatının orta parçası, iç çevresi üzerinde, bir kaburganın bir ahşabı sabitlenerek bir ahşap, merkezi diskten geçen, çapı bir buçuk ile iki metre civarında olan sert bir ahşap kasnaktan oluşur. Çemberin dış çevresine, açıldığında bir şemsiyenin şeritleri gibi aşağı doğru kıvrılmak üzere bir dizi ayrı kaburga yerleştirilebilir. Böylece üç buçuk ile dört buçuk metre çapında bir çatı oluşturulur ve bu yapıda büyük bir güçle hafiflik birleştirilir. Duvar, mandallar veya çivilerle değil birbirlerine düğümlenmiş kısa iplikler ile tutturulmuş kaburgalardan yapılmış ayrı kafes parçalarından oluşur. Her iki uç da kafes işinin tamamı çok esnek olacak şekilde, çadır kurulduğunda kolayca kapatılabilir ve zedelenmeden taşınabilir. Çadırı kurmak için kavisli kaburgalar kasnağın dış çevresine yerleştirilir. Ayrı kafes setleri bir daire içinde birbirine bağlanır. Böylece duvar

10 Henry J. Van Lennep, Bible Lands: Their Modern Customs and Manners Illustrative of Scripture (New York: Harper \& Brothers, Publishers, 1875), 400.

11 Henry J. Van Lennep, Travels in Little-Known Parts of Asia Minor; with Illustrations of Biblical Literature and Researches in Archeology, (London: Printed by W. Clowes And Sons, 1870), II: 216.

12 Georges Perrot ve Charles Chipiez, History of Art in Phrygia, Lydia, Caria and Lycia (London: Printed by Chapman and Hall Limited, 1892), 70.

13 John Macdonald Kinneir, Journey Througe Asia Minor, Armenia, and Koordistan, in the Years 1813 and 1814; with Remarks on the Marches of Alexander, and Retreat of the Ten Thousand (London: Printed by John Murray, 1818), 58. 
oluşturulur ve çatı kaburgaları üstte sıkıca tutturulur. Bu çerçeve birlikte sabitlendiğinde çok sağlamdır ve ortada biraz içe doğru eğilen kafes şekliyle sabitlenir ve böylece kafes duvarı bir zar kutusu şeklinde yukarıdan aşağıya doğru biraz uzanır. Bundan sonra çadır aksamının dış kısmının tamamı kalın ve kaba keçelerle kaplanır. Bunun için sekiz küçük veya altı büyük keçe gerekir. Bunlar, çerçeveye ve birbirlerine sıkıca dikilir. Böylece rüzgâra ve havaya dayanıklı bir çadır oluşur hatta içinde bir ateş bile yanabilir. Ayrıca yan bezlerin bir kısmı kaldırılarak yaz aylarında çadırın içerisi serin tutulabilir. Bu çadırlar, kışın ovaları sıklıkla kullanan Türkmenlerin tek konutu olarak gösterilir. Bu ayrıntılı betimlemeden sonra gezgin, çadır iskeleti ve örtülerinin yapımı ile fiyatına da değinmekle birlikte çadır çerçeveleri Kayseri'de yapıldığı gibi yaklaşık 250 kuruşa mal olur. Kafes içerisindeki her bir kaburga çifti sabitlendiğinde maliyeti yaklaşık 1 kuruş eder. Keçe örtü kumaşları Niğde, Bor ve çevresinde üretilirken her biri yaklaşık 60 kuruşa mal olur. Verdiği bilgilerden sonra işçiliği göz önüne alan gezgin tarafından bu çadırların fiyatının inanılmaz derecede düşük olduğu belirtilir. ${ }^{14}$

Gezgin Percy ise Ereğli'den sonra Hasandağı ve Karacadağ ile Toroslar arasında bulunan Türkmenlerin, yuvarlak biçimli çadırlarının bükülmüş sepet şeklinde yapıldığını ve üst kısmı açık olup üstünün beyaz keçelerle örtüldüğünü ifade eder. ${ }^{15}$

Gezginler tarafindan verilen bu bilgiler ve betimlemelerden sonra topak evin güney, batı ve iç kesimler dâhil olmak üzere Türk coğrafyasında yaşayan konargöçerler arasında yaygın bir kullanım alanının olduğu görülür.

\section{Karaçadır}

Yörük veya Türkmen kitlesi tarafından mesken olarak kullanılan önemli bir çadır türü karçadır, kıl çadır, çul çadır gibi adlarla anılan ve keçi kılından dokunan çadır olup ${ }^{16}$ gezginler gözlemlerinde karaçadır adından ve donanımından sıklıkla bahsederler. $\mathrm{Bu}$ çerçevede 17. yüzyılın ikinci yarısında Çekerek yakınlarında olduğu muhtemel birçok Türkmen ile karşılaştıkları küçük bir derenin kıyısında konaklayan gezgin Tavernier, Türkmenleri Araplar gibi çadırlarda yaşayan bir ulus olarak nitelendirip hatta o sırada öküzlerin çektiği kağnılara eşyalarını yükleyip oradan ayrılmak üzere olduklarını belirtir ki burada bahsedilen karaçadır olmalıdır. ${ }^{17}$ Yine Reyhanlı Türkmenleri ile ilgili 1810 yılında verilen bilgilere göre bunların yaşadıkları çadırlar, yaklaşık bir buçuk metre yüksekliğindeki gevşek taşlardan oluşan dikdörtgen bir duvar, bir düzine veya daha fazla direk tarafından desteklenen, keçi kılından dokunmuş siyah bir çul ile örtülür. Çadırın ortasında örtü yerden direkler vasıtası ile yaklaşık iki metre yetmiş beş santimetre yükselir. Girişin yanına taş bir bölme inşa edilir ve her çadırda

14 Davis, Life in Asiatic Turkey, a Journal of Travel in Cilicia, (Pedias and Trach(ea) İsauria, and Parts of Lycaonia and Cappadocia, 265-267.

15 Earl Percy, Highlands of Asiatic Turkey (London: Printed by Enbia Office, 1901), 50.

16 Ak, Teke Yörükleri (1800-1900), 108.

17 John Baptista Tavernier, The Six Voyages of John Baptista Tavernier, a Noble Man of France Now Living, through Turky into Persia and the East-Indies (London: Printed for R. L. and M. P., 1678), 39; Jean Baptiste Tavernier, Tavernier Seyahatnamesi, çev. Teoman Tunçdoğan (İstanbul: Kitap Yayınevi, 2006), 129. 
kadınlar, kapının solundan çadırın daha büyük bir yarısında işlerini yaparlar. Sağ taraftaki daha küçük olan yer erkeklere ayrılırken, ayrıca ara boşlukta, aile reisinin veya oğullarından birisinin en sevdiği atı için ahır olarak hizmet eden bir bölüm bulunur. Kadın odası, erkek odası ve ara geçiş bölümünden oluşan çadırın uzunluğu yirmi ile otuz metre arasında değişir. Çadırlardaki kadın odası aynı zamanda mutfak olarak da hizmet verir hatta bu bölümde kurulan tezgâhlarda kadınlar dokuma işleri ile uğraşırlar. Halılarla kaplanan erkekler bölümü yabancılara ve ailenin bekâr üyelerine yatak görevi görür. Evlenenler, kadınların bulunduğu bölümden ayrılırlar. ${ }^{18}$

Halep ile Antakya arasında yaşayan Bedeviler veya Türkmenlere ait karaçadırların varlığından söz edildiği ${ }^{19}$ gibi çadır ve göçebe hayat başlığı altında karaçadır, Arap çadırı olarak ele alınır ve tanıtılır ancak bu çadır, Türk coğrafyasında yaşayan Yörükler veya Türkmenler tarafından yaygın olarak kullanılır. Karaçadırın en eski dönemlerden beri var olduğu belirtilmekle birlikte her zaman siyah veya koyu kahverengi keçi kılından yapılan çadır kanatlarının, çadırın içerisinde hane kadınları tarafından uzun şeritler hâlinde istenilen genişlikte dokunduğu ve kenarlarından birbirine dikildiği beyan edilir. Bu çadır bezi su geçirmediği gibi güneş ışınlarını emme özelliğine sahip olup akçadır olarak da belirtilen topak evden daha soğuk olduğu dile getirilir. Çul kanatlar, çadırın uzunluğu yönünde uzanan bir paralelkenar şeklinde iken giriş, uzun kenarlardan birindedir. Çadır, ahşap direkler tarafından desteklendiği gibi bunların sayıları değişken olup bazen yirmi dörde kadar çıkabilir. Bununla birlikte normal sayı çadırın genişliği boyunca üç sıra hâlinde ayarlanmışsa dokuzdur. Çadır kanadının sınırı boyunca aralıklarla çadır çivilerine ilmeklerle tutturulmuş çadır bağları bağlanır. Bu çadır çivileri, daha kalın uçlarında bir çentik bulunan yaklaşık bir metre uzunluğunda çivi adı verilen ağaç kazık veya mandallar olarak adlandırılır. Tahta bir tokmak veya çekiçle sağlam bir zemine yerleştirilip sıkıca yere çakılırlar. Bir çadır kurulurken çadırın kenarından sırayla her bağ çekilerek yere çakılan bir kazığın ilmeğine geçirilir ve gerilir. $\mathrm{Bu}$, birkaç kişinin iş birliğini gerektirir ve genellikle kadınlar ile çocuklar tarafından yapılır. Çadır çulu böylece zeminin üzerinde kayda değer bir yüksekliğe ulaştırılır ve giriş dışında, kıldan dokuma perdeler olarak bahsedilen çadır sitilleri veya kamıştan yapılan hasır ile alan daha serbest bir hava dolaşımı sağlayacak şekilde kapatılır. İç kısım, üç merkez direğe asılan bir perde ile iki eşit parçaya bölünür. Güneydoğu'da sol taraf hanenin erkek üyeleri tarafından kullanılırken giriş önünde ve bölme perdenin yanında sağ taraf kadınların kullanım alanı olarak betimlenir. ${ }^{20}$

Teke Yöresi'nde Korkuteli hattında Yazır Ovası'nda rastlanılan çadırlar, üst uçlarından birbirlerine bağlı yere çakılmış üç direk üzerine kurulmuş dış cepheden asılan çullar olarak adlandırılan çadır sitilleri ile bir iç mekân oluşturulduğu şeklinde tanımlanır. Ayrıca içerde yakılan ateş nedeni ile oluşan dumandan, tek bir kapıdan başka çıkış ve hava alma yeri olmayan

18 Burckhardt, Travels In Syria And The Holy Land, 636.

19 Julius Seiff, Reisen in der Asiatischen Türkei (Leipzig: J. C. Hinrichs'sche Buchhandlung, 1875), 313.

20 Lennep, Bible Lands: Their Modern Customs and Manners Illustrative of Scripture, 400-402. 
çadırda bunaltıcı bir ortam oluştuğu ancak bu duruma rağmen burada yaşamaya alışkın hayvancilıkla uğraşan kişilerin özgür ve mutlu göründükleri belirtilir. ${ }^{21}$ Yine Teke Yöresi'nde Seyret'e doğru gidilirken dik bir dağ üzerinden geçilen noktada rastlanılan yer ve çevresinde Türkmenlerin karaçadırlarının kurulu olduğu belirtilirken ${ }^{22}$ Bucak hattında Bademağacı'ndan Kavacık köyüne giden yol çevresinde bulunan Yörük bolluğu ve karaçadırlardan bahsedilir. ${ }^{23}$ Bucak ile Antalya arasında bir Yörük Beyi’ne ait açık, kaba, siyah keçi kılı çadır, üç direkle desteklendiği gibi her bir tarafı gevşek taşlarla örülmüş olup öndeki direğe Bey’in uzun silahı ve mızrağı asılmış durumdadır. Çadırın içi halılar ve minderler ile döşeli iken içeride yanan ateş ve köz üzerinde bir tava bulunduğu gibi soluk 1şıkta, çadırın siyah çatısının altından dumanın kıvrılarak çıktığı belirtilir. ${ }^{24}$

Eğirdir ve Ada'nın da görülebildiği bir noktadan göl kıyısına yakın bir yerde gezgin Arundell'in deyimi ile çok sayıda Türkmen veya Yörük ailesi yaşamaktadır. Her birinde iki ya da üç kadın bulunan karaçadırlarda zemine sabitlenmiş basit dokuma tezgâhlarında halı dokunduğu belirtilir ki ${ }^{25}$ yöre genellikle Teke Yöresi'nden ve özellikle Serik muhitinde kışlayan Yörüklerin yaz aylarında çıktıkları Anamas yaylalarının bulunduğu çevredir. Aynı yörede Sultan Dağı'nda, Ketenlik Yaylası'nda, görülen Yörük çadırları koyu renk, su geçirmez keçi kılından yapıldıkları gibi sahip olduğu gevşeklik ile gün 1 şı̆̆ı içeriye girebilmektedir. Dikdörtgen şeklindeki çadır direklerle ayağa kaldırılırken bu direklerin aynı zamanda dışarıdaki ağaç gövdelerine veya yere çakılmış kısa çivilere de bağlı olduğu belirtilir ancak çadır, kanatları ucundaki bakaralardan geçirilen bağlar ile çivilere bağlanır. Ayrıca gezgin Sarre, girdiği çadırın içinin çok geniş olduğunu içeride iskemle görevini gören çok sayıda çuval ve yatağın bulunduğunu beyan eder. ${ }^{26}$

Karaman Yöresi'ne yakın Altıntaş Dağı'nda yaylayan Yörüklerden dul bir kadının çadırında misafir edilen gezgin Davis, kaldığı çadırı iyi olarak nitelendirir. Çadırın iç

21 Louis Alexandre Olivier Corancez, Itineraire d'une Partie Peu Connue de L'Asie Mineure (Paris: De l'imprimerie de P. Gueffier, Rue Guenegaud, 1816), 396-397.

22 T. A. B. Spratt ve Edward Forbes, Travels in Lycia, Milyas, and the Cibyratis, (London: Printed by S. \& J. Bentley, Wilson and Fley, 1847), I: 59; T. A. B. Spratt ve Edward Forbes, Milyas, Kibyratis ve Likya'da Yolculuklar, çev. Doğan Türker (Antalya: Suna-İnan Kıraç Akdeniz Medeniyetleri Araştırma Enstitüsü Yayını, 2008), I: 59.

23 E. J. Davis, Anatolica; or, the Journal of a Visit to Some of the Ancient Ruined Cities of Caria, Phrygia, Lycia, and Pisidia (London: Grant and Co., Printers, 1874), 203; E. J. Davis, Anadolu XIX. Yüzyılda Karya, Frigya, Likya ve Pisidya Antik Kentlerine Yapılan Bir Gezinin Öyküsü, çev. Funda Y1lmaz (İstanbul: Arkeoloji ve Sanat Yayınları, 2006), 156.

24 Charles Fellows, A Journal Written During an Excursion in Asia Minor (London: Printed by Richard and John E. Taylor, 1839), 177; Charles Fellows, Travels and Researches in Asia Minor, More Particularly in the Province of Lycia (London: Printed by John Edward Taylor, 1852), 131-132.

25 Fr. V. J. Arundell, Discoveries in Asia Minor; Including a Description of the Ruins of Several Ancient Cities, and Especially Antioch of Psidia, (London: Publisher in Ordinary to this Majesty, 1834), I: 330.

26 Friedrich Sarre, Reise in Kleinasien (Sommer 1895) Forschungen Zur Seldjukischen Kunst und Geographie des Landes (Berlin: Druck Von Otto Elsner, 1896), 116-117; Friedrich Sarre, Küçükasya Seyahati (1895 Yazı) Selçuklu Sanatı ve Ülkenin Coğrafyası Üzerine Araştırmalar, çev. Dârâ Çolakoğlu (İstanbul: Pera Turizm ve Ticaret A.Ş. Yayını, 1998), 143. 
donanımı ile ilgili verilen bilgiye göre çadırda, kadının kocasının silahı ve kılıcı yerinde asılı iken çadır birçok keçi kılı çuval, buğday ve diğer eşyalar ile doludur. Misafir ettiği gezginin uyuması için ev sahibi kadının deriden yapılmış bir kılıftan güzel bir kilim çıkarıp gezgini en iyi annelik duyguları ile örttükten sonra kızının çadırına çekildiği dile getirilir. ${ }^{27}$

Efes'te 1824 yılı ocak ayında harabeler içerisine kurulu olan, Türkmenlere ait, karaçadırlardan bahsedilir. Aydın Yöresi'nde Güzelhisar'a giderken Okluk köyü yanında büyük bir Türkmen obası gören gezgin Arundell, bu Türkmenlere ait karaçadırların yanı sıra dairesel bir şekle sahip başka çadırlar da vardı derken burada karaçadırların yanında topak evin de varlığı ve kullanıldığı dikkatleri çeker. Pamukkale’ye gidilirken yolda Türkmen karaçadırlarının görüş açılmadan bir anda yükseldiği belirtilirken Eskihisar ve Pamukkale çevresi ile Küçük Menderes havzasında Türkmenlere ait çok sayıda karaçadırın varlığından söz edilir. ${ }^{28}$

Yine Efes harabeleri yakınında Türkmenlere ait karaçadırlarla kaplı bir bataklığa gelen Michaud ve Poujoulat, karşılaşılan manzarayı, çıplak çocuklar, güneşte kararmış vahşi görünüşlü kadınlar ve erkekler, kimisi çadırların altında kimisi de dışında, sığırlar ve keçilerin ortasında, sazların üzerine yaydıkları ağların yanında oturdukları şeklinde tasvir ederler. Bu barbar kabile, bu karaçadırlar ve deniz kıyısında bu sürü, bizim için o kadar garip ve yeni bir manzaraydı ki, bakmaktan kendimizi alamıyorduk ancak biz, bu kabileden hiç kimsenin dikkatini çekmedik. İnanır mısınız? Bir yabancı ve Avrupalı, çevrede otlayan keçilerin ne kadar dikkatini çekerse, bu adamların da o kadar dikkatini çekti ${ }^{29}$ beyanına göre bekledikleri ilgiyi göremedikleri için yöredeki Türkmenler, oryantalist bakış açısı ile barbar kabile olarak nitelendirilir.

Menderes Vadisi'nde dağların aşağı tepelerinin eğimli yeşilinin olduğu yerlerin, Yörüklerin karaçadırlarıyla beneklendiği beyan edilirken ${ }^{30}$ yöredeki ovalara dağılan Yörüklerin karakeçi kılı çadırları ${ }^{31}$ ile yine aynı çevrede Gediz Irmağı havzasında Taşköy yakınında Yörüklerin çevreye dağılmış karaçadırları ${ }^{32}$ yanında Sart'ta Yörüklere ait karaçadırların varlığından söz edilir. ${ }^{33}$

İzmir Yöresi'nde, hiçbir toprağı bulunmayan, az miktarda koyun sürülerine ve nakliye

27 Davis, Life in Asiatic Turkey, a Journal of Travel in Cilicia, (Pedias and Trach(ea) İsauria, and Parts of Lycaonia and Cappadocia, 360.

28 Arundell, A Visit to the Seven Churches of Asia; with Excursion into Psidia; Containing Remarks on the Geography and Antiquities of those Countries, 56, 60, 77, 91, 205, 208.

29 M. Michaud ve M. Poujoulat, Correspondance d'Orient 1830-1831 (Paris: Ducollet, Libraire-Eduteur, 1833), I: $281-282$.

30 Charles Fellows, An Account of Discoveries in Lycia, Being a Journal Kept During a Second Excursion in Asia Minor (London: Printed by Richard and John E. Taylor, 1840), 50; Fellows, Travels and Researches in Asia Minor, More Particularly in the Province of Lycia, 263.

31 Fellows, Travels and Researches in Asia Minor, More Particularly in the Province of Lycia, 236.

32 Henry J. Van Lennep Travels in Little-Known Parts of Asia Minor; with Illustrations of Biblical Literature and Researches in Archeology, II: 266.

33 William J. Hamilton Researches in Asia Minor, Pontus, and Armenia; with Some Account of their Antiquities and Geology, I: 146. 
için kullandıkları sürekli kâr getiren develere sahip olan, gezgin Hawley’in oryantalist bakış açısı ile göçebe Türkmen kanı ve Çingene içgüdüsüne sahip dediği Yörüklerin, karakeçi kılından dokunan üç metre çapında ve bir buçuk metre yüksekliğinde çadırlarda oturdukları belirtildiği gibi yine yörede nehir kıyısındaki alçak tepelerde yaşayan Yörüklerin sıklıkla deve ve karaçadırlarının görüldüğü ifade edilir. ${ }^{34}$

Uludağ'da yaşayan ve gezgin Texier tarafından konargöçer Türkmen olarak tanımlanan Yörüklerin yaylada kurdukları topak ev dışında kullandıkları bir diğer çadır türü, keçi kılından veya koyun yapağısından dokunan karaçadır olarak tanımlandığ $1^{35}$ gibi bu yörede karaçadır dokumasında koyunyünü de kullanıldığı anlaşılmaktadır.

Karadeniz Bölgesinde, Ordu'dan sonra ulaşılan Ünye Yöresi'nde, Türkmenlere ait çok sayıda karaçadırdan bahsedildiği gibi Çorum Ovası'ndaki Türkmenlerin çadırları, keçi kılından yapılan kalın siyah çul olup direkler üzerine gerilerek kurulduğu belirtilir. Yine Alaca Çayı'nı takiben Alaca Ovası'na doğru gidilirken rastlanılan Türkmenlere ait çadırların keçi kılından yapıldığı ve bunların direkler üzerine gerildiği belirtilirken kenarları birbirine tutturulmuş ince sazlar olarak bahsedilen hasırlar, kazıklar ile desteklendiği gibi bunlar içeriye havanın serbestçe girmesini sağlar. Ayrıca gezgin Hamilton, ülkenin bu bölümünde İzmir ve iç kesimlerde yaşayan Türkmenlerin kullandığı düşük yuvarlak kubbe şeklindeki çadırları görmediğini belirtir. ${ }^{36}$

Bütün bunlardan sonra gezginlerin verdikleri bilgiler çerçevesinde karaçadırın Türk coğrafyasında geniş bir alanda konargöçer kitle arasında yaygın bir kullanım alanının olduğu söylenebilir.

\section{Alaçık}

Alaçık genellikle Teke Yöresi’nde yaşayan bir kısım Yörükler tarafından kullanılan bir çadır türüdür. Ağaçlardan kesilen iki veya üç metre uzunluğundaki çubukların kalın tarafları ortalama yarım metre aralıklarla yere çakılarak ince uçları üstte karşılıklı olarak eğilip bağlandığı gibi tünel biçimini alan yapının üzerine eski çul, kilim ve keçe örtülerek kurulmaktadır. ${ }^{37}$ Gezginlerin gözlemlerinde bahsedilen Teke Yöresi'nde Kaş’a bağlı Çerler köyünde bereketli bir bahar otlağının ortasında, birkaç Türkmen kulübesi denilen çadır ile yine Kaş'a bağlı Gelemen'de dar bir çukurun veya geçidin dibinde yarım düzine kadar, buna eşit sayıdaki Türkmen ailesinin barınağı olan yuvarlak karaçadırlar şeklinde betimlenen ${ }^{38}$ çadır türü, üzerine keçi kılından dokuma kara çul örtülen alaçıktır.

Aynı yöredeki Bucak’a bağlı Kavacık köyü halkının içinde barındığı kamış ve hasırlarla

34 Walter A. Hawley, Asia Minor (New York: Printed by William Brendon and Son LTD., 1918), 91, 138.

35 Texier, Küçük Asya Coğrafyası Tarihi ve Arkeolojisi, 1: 231.

36 William J. Hamilton Researches in Asia Minor, Pontus, and Armenia; with Some Account of their Antiquities and Geology, I: 275, 381, 384-385.

37 Ak, Teke Yörükleri (1800-1900), 107.

38 Spratt ve Forbes, Travels in Lycia, Milyas, and the Cibyratis, I: 112, 119; Spratt ve Forbes, Milyas, Kibyratis ve Likya'da Yolculuklar, I: 112, 119. 
çevrili çubuklardan yapılmış çok sayıda kulübe ${ }^{39}$ ile Ksanthos Vadisi’ndeki Yörük çadırı olarak bahsedilen çadır da alaçık olup özellikle buradaki alaçıkların, keçi kılından dokunmuş çullar ile örtülü bölümünde aile, sazlarla çevrili öbür bölümdeyse hayvanların barındığı belirtilir. ${ }^{40}$

\section{Huğ ve Diğer Meskenler}

Reyhanlı Türkmenlerinden, çadırlarda yaşayanların yanı sıra ovadakilerin inşa ettikleri kulübelerde yaşadıkları belirtilir ki ${ }^{41}$ buna yörede huğ adı verilir. Huğ, çadırları andıran bir yapı olup yere çakılan dikmeler üzerine uzatılan merteğe çakılan kalaslar üzerine bataklıklardan kesilen kamışlar örtülür. Yine etrafı belirli aralıklar ile çakılan uzun çivilerin arasına sazlardan örülen çit ile çevrilir. ${ }^{42}$ Bu yapıya benzer başka bir gözlemde gezgin Arundell, Pamukkale'ye giderken seyahat ettiği yol üzerinde, karaçadırların bulunduğu geniş bir Türkmen obasına geldiği gibi burada bu çadırların yanı sıra farklı şekilde inşa edilen kulübelerin varlığından söz eder. Bunların bazılarının düzenli olarak tüm açmaları ile kerpiçten; bazılarının ise basitçe uzun kamış demetleri ile birbirine yaslanarak bir açı oluşturacak şekilde inşa edildiklerini ${ }^{43}$ belirtir ki yörede karaçadır ile birlikte bu yapıların bir arada kullanıldığı görülmektedir.

Yine Ceyhan Toprakkale civarında yaşayan Türkmenlerin konutları, kil ile sıvanmış çubuklar ve kamıştan oluşan kulübe olarak betimlenirken ${ }^{44}$ Sart yakınlarındaki Yörüklerin kamıştan yapılan kulübe de oturdukları, ${ }^{45}$ Akşehir Gölü yakınlarındaki Yörüklerin ise yabani kümes hayvanlarıyla iç içe bir gölün sınırında bulunan kamışları kesip yazlık evlerini inşa ettikleri belirtilir. ${ }^{46}$

Gezginlerin gözlemlerinde isim belirtilmeksizin bahsedilen meskenler de olup 13. yüzyılın sonlarında Tarsus ve Çukurova üzerinden Türkiye olarak adlandırdığı Orta Anadolu'da Kayseri Yöresi'ne gelen gezgin Crucis, burada kendilerini genelde köstebek gibi yer altında yaşayan Müslüman Türkmenler arasında bulduklarını ve bu Türkmenlerin duvara benzer toprakla örtülü mağaralarından çıkageldiklerini ifade eder. ${ }^{47}$

Asi Irmağı kıyısındaki Türkmenlerin yaşadıkları köylerin saman kaplı yuvarlak kulübelerden oluştuğu belirtilmekle birlikte bu konutların esin kaynağının topak ev olduğu

39 Davis, Anatolica; or, the Journal of a Visit to Some of the Ancient Ruined Cities of Caria, Phrygia, Lycia, and Pisidia, 203; Davis, Anadolu XIX. Yüzyılda Karya, Frigya, Likya ve Pisidya Antik Kentlerine Yapılan Bir Gezinin Öyküsü, 156.

40 Ernst Krickl, 1892 Lykia Günlüğü, çev. Z. Zühre İlkgelen, Filiz Dönmez Öztürk (İstanbul: Suna ve İnan Kıraç Vakfi-Arkeoloji ve Sanat Yayınları, 2005), 142, 238, 293.

41 Burckhardt, Travels in Syria and the Holy Land, 636.

42 Şemsettin Mursaloğlu, Büyük Reyhanlı Türkmen Aşireti Tarihi (İzmir: Karınca Matbaacılık, 1984), 174-175.

43 Arundell, A Visit to the Seven Churches of Asia; with Excursion into Psidia; Containing Remarks on the Geography and Antiquities of those Countries, 75.

44 Davis, Life in Asiatic Turkey, a Journal of Travel in Cilicia, (Pedias and Trach(ea) Isauria, and Parts of Lycaonia and Cappadocia, 77.

45 Francis E. Clark, The Holy Land of Asia Minor (New York: by Charles Scribner's Sons, Published, 1914 ), 100.

46 Hawley, Asia Minor, 211-212.

47 Ricoldus De Monte Crucis, Doğu Seyahatnamesi Bir Dominikan Keşişin Anadolu ve Ortadoğu Yolculuğu, çev. Ahmet Deniz Altunbaş (İstanbul: Kronik Kitap Yayınları, 2018), 42. 
söylenebileceği gibi daha sık olarak Türkmenlerin çadırlarda yaşadıkları ve toplantılarında bir obanın şehirden daha iyi göründüğü beyan edilir. ${ }^{48}$

Denizli Yöresi'nde Eskihisar harabeleri içerisinde bulunan Türkmen kulübeleri ve çadırlardan bahsedilirken yine aynı yörede Çardak hattında bulunan Çorak Göl yakınındaki dağın kenarında birkaç Türkmen kulübesi olduğu belirtilir. ${ }^{49}$

Çadır türü ve adı belirtilmeksizin Bucak yakınlarındaki Kremna antik kentine doğru giden gezgin Arundell, bir kulübe yanında durduklarını ve Türkmenlerin çadırlarının olduğu düz bir alana geldiklerini beyan ederken ${ }^{50}$ Ankara' da Çubuk Ovası'nı dolaşan Çubuk Suyu kenarında bulunan Çubuk köyünden bahsedilirken de yazın burada birçok Türkmen çadırının görüldüğü dile getirilir. ${ }^{51}$

Yine tür ve adı verilmeksizin çadırların yapım ve donanımından bahsedildiği durumlarda olup gezgin Taylor, Antakya Ovası'nda, Türkmen çadırlarının bulunduğu yerde misafir olduğu bey çadırının deve yünü dokumadan yapıldığını, ferah ve yanlardan açık olduğunu, çadırda kendisi için bir halı serildiğini belirtir. ${ }^{52}$ Gezgin Davis ise Çiftehan'dan sonra rastlanan dağınık Türkmen obalarından sonuncusunun çadırlarını geniş, sağlam ve kalın deve yününden yapılma; iyi halılar ve minderler ile döşeli olarak tarif eder. Aynı gezgin, Mut sınırları içerisinde yer alan Mavga yaylasında misafir olduğu Yörük çadırını temiz, en iyi kilimler serili ve güzel kokulu ardıç odunu ateşinin yakıldığı şekilde anlatır. Altıntaş Dağı'nda yaylayan Yörüklerin çadırlarına geldiğinde ise bunların o yörede son insan yerleşimi olduğunu dile getirip, mümkün oldukça, her zaman bir köyden ziyade, bir Yörük obasında kaldığını, insanların kendileri kibar ve misafirperver, çadırları genel olarak düzenli ve temiz yorumunu yapar..$^{53}$

Ayrıca Kütahya hattında Kümbet köyünden sonra devam eden yolculuk boyunca yol üzerinde yarı göçebe olarak nitelendirilen Yörük oymağının yaz aylarında, keçeden yapılmış yumurta şeklindeki çadırlar yanında çerçevesiz keresteden yapılmış barakalarda oturdukları belirtilir. Bu ağaçtan yapılan odalarda çerçeve, kelepçeler veya pimler olmadan bir araya getirilir. Duvarlar için kirişler mümkün olduğunca yan yana döşenip, dört köşede birbirinin üstüne, üst üste gelecek şekilde yapılır. Yerlerinde sağlam kalmaları için, alt kirişler kalınlığının yaklaşık yarısına kadar geçirilir. Çatı da benzer şekilde yatay olarak yerleştirilmiş, kavisli bir iskelet oluşturacak şekilde inşa edilmiş kaba çerçevesiz kirişlerden oluşur. Bunun üzerine

48 Corancez, Itineraire d'une Partie Peu Connue de L'Asie Mineure, 143.

49 Arundell, A Visit to the Seven Churches of Asia; with Excursion into Psidia; Containing Remarks on the Geography and Antiquities of those Countries, 85, 154.

50 F. V. J. Arundell, Discoveries in Asia Minor; Including a Description of the Ruins of Several Ancient Cities, and Especially Antioch of Psidia, (London: Publisher in Ordinary to this Majesty, 1834), II: 59.

51 Charles Texier, Küçük Asya Coğrafyası Tarihi ve Arkeolojisi, çev. Ali Suat (Ankara: Enformasyon ve Dökümantasyon Hizmetleri Vakfi Yayını, 2002), 2: 476.

52 Bayard Taylor, the Lands of the Saracens; or, Pictures of Palestine, Asia Minor, Sicily and Spain (New York: Printer, Stereotyper and Electrotyper, Carton Building, 1859), 217.

53 Davis, Life in Asiatic Turkey, a Journal of Travel in Cilicia, (Pedias and Trach(ea) Isauria, and Parts of Lycaonia and Cappadocia, 223-224, 330, 359. 
döşeyebildikleri kadar sıkı kare direkler denilen atkılar yerleştirilir. ${ }^{54}$

Yörükler ile yerleşiklerin oturdukları konutların karşılaştırıldığı durumlar da olup İzmir Yöresi’ndeki vadilerde yaşayan, köylülerin evleri çoğunlukla eğimli kiremit çatılı kerpiç iken dağlarda, açık alanlardan toplanmış kaba taş duvarları ile yabani otların kök saldığı toprak düz çatıları olan ilkel konutların birçoğunun, koyun sürüleri ve deve katarları bakımından nispeten zengin olan Yörüklere ait olduğu belirtilir. ${ }^{55}$

\section{Sonuç}

Yörük veya Türkmen olarak adlandırılan Türk konargöçerlerinin kullandığı çadır türleri çeşitlilik göstermekle birlikte bunlar topak ev, derim evi; karaçadır, kıl çadır, çul çadır; alaçık gibi çadır türleri ile saz bitkisinden yapılan huğ adı verilen meskenler yanında taş veya ahşaptan inşa edilen meskenler olup bunların bazen aynı ortamda bir arada kurulup kullanıldıkları da görülür. Çadırlar, yöreye göre bazı kısmi farklılıklar gösterebilir ancak hammadde, dokuma, kurulum ve donanım gibi özellikleri çoğunlukla benzerdir.

Kullanılan çadır veya diğer mesken türleri konargöçer kitlenin kışlak, yaylak ve güzlek arasındaki en önemli barınakları olup kurulum ve taşınma kolaylığı ile hareketli yapıya uygundur.

Gezginler, genel olarak çadırlar ile diğer konutları birebir görüp betimlerlerken çoğu zaman romantik bir bakış açısı ile hayranlıklarını gizleyemeyenler olduğu gibi zaman zaman değerlendirmelerinde oryantalist bakış açısından kurtulamayanlar da vardır. Çadırların şekli, donanımı, yapımı, kullanım alanı ve bölümleri genellikle ayrıntılı olarak betimlenirken isim ve tür belirtilmeksizin genel tanımlamalar da yapılmıştır. Yine çadırlar ile ilgili verilen çizimler veya resimler, betimlemelere canlılık katması ve ortamın hafızalarda canlandırılması bakımından önemlidir.

Yörük veya Türkmen kitlesi, farklı çadır türlerini bir arada kullandıkları gibi bir çadır yanında bir de sabit bir meskenin varlığı gezginlerin anlatımında ve betimlemelerde dikkat çeker. Çoklu mesken kullanımı oturulan yerlerin aynı olması ve mevsim farkına bağlı hareketli yapının belirli mekânlar arasında sürdürüldügünü göstermesi bakımından önemli olduğu kadar gündelik hayat içerisinde aile bireylerinin kalabalıklığı ile de ilgilidir.

Gezginlerin misafirler için ayrı bir çadır kurulduğunu belirtmeleri, toplumun bu kısmının sergilediği Türk misafirperverliğinin önemli bir göstergesidir.

Türk çadır mimarisinin yerleşim boyutu ile yerleşenlerin yaptıkları konutları etkilediği de meskenlerle ilgili betimlemelerden anlaşılan önemli bir husustur.

Türk coğrafyasında genel olarak Yörük veya Türkmen kitlesinin yaygın olarak kullandıkları çadırlar topak ev ile karaçadır olarak dikkat çekerken bazı yörelerde alaçık, huğ ve diğer mesken türlerinin kullanıldığı görülmekle birlikte bunların bulundukları yerlerdeki

54 Perrot ve Chipiez, History of Art in Phrygia, Lydia, Caria and Lycia, 70.

55 Hawley, Asia Minor, 202. 
mevcut şartlar ve ortam içerisinde zengin bir konut yapım ve kullanım anlayışına sahip oldukları söylenebilir.

\section{Kaynaklar}

Ak, Mehmet. Teke Yörükleri (1800-1900). Ankara: TTK Yayınları, 2015.

Arundell, Fr. V. J. A Visit to the Seven Churches of Asia; with Excursion into Psidia; Containing Remarks on the Geography and Antiquities of those Countries. London: Published by John Rodwell, 1828.

Arundell, Fr. V. J., Discoveries in Asia Minor; Including a Description of the Ruins of Several Ancient Cities, and Especially Antioch of Psidia. Volume I. London: Publisher in Ordinary to this Majesty, 1834.

Arundell, Fr. V. J., Discoveries in Asia Minor; Including a Description of the Ruins of Several Ancient Cities, and Especially Antioch of Psidia. Volume II. London: Publisher in Ordinary to this Majesty, 1834.

Burckhardt, John Lewis. Travels in Syria and the Holy Land. London: Published by the Association for Promoting the Discovery of the İnterior Parts of Africa, 1822.

Clark, Francis E. The Holy Land of Asia Minor. New York: By Charles Scribner's Sons, Published, 1914.

Corancez, Louis Alexandre Olivier. Itineraire d'une Partie Peu Connue de L'Asie Mineure. Paris: De l'imprimerie de P. Gueffier, Rue Guenegaud, 1816.

Crucis, Ricoldus De Monte. Doğu Seyahatnamesi Bir Dominikan Keşişin Anadolu ve Ortadoğu Yolculuğu. Çeviren Ahmet Deniz Altunbaş. İstanbul: Kronik Kitap Yayınları, 2018.

Davis, E. J. Anatolica; or, the Journal of a Visit to Some of the Ancient Ruined Cities of Caria, Phrygia, Lycia, and Pisidia. London: Grant and Co., Printers, 1874.

Davis, E. J. Life in Asiatic Turkey, a Journal of Travel in Cilicia, (Pedias and Trach(ea) Isauria, and Parts of Lycaonia and Cappadocia. London: Printed by Edward Stanford, 1879.

Davis, E. J. Anadolu XIX. Yüzyılda Karya, Frigya, Likya ve Pisidya Antik Kentlerine Yapılan Bir Gezinin Öyküsü. Çeviren Funda Yılmaz. İstanbul: Arkeoloji ve Sanat Yayınları, 2006.

De Chateaubriand, F. A. Itineraire de Paris a Jerusalem et de Jerusalem a Paris. Tome Second. Paris: Le Normant, İmprimeur-Libraire, 1812.

De La Broquiere, Bertrandon. Bertrandon De La Broquiere'in Denizaşırı Seyahati. Çeviren İlhan Arda. İstanbul: Eren Yayınları, 2000.

Fellows, Charles. A Journal Written During an Excursion in Asia Minor. London: Printed by Richard and John E. Taylor, 1839.

Fellows, Charles. An Account of Discoveries in Lycia, Being a Journal Kept During a Second Excursion in Asia Minor. London: Printed by Richard and John E. Taylor, 1840.

Fellows, Charles. Travels and Researches in Asia Minor, More Particularly in The Province of Lycia. London: Printed by John Edward Taylor, 1852.

Hamilton, William J., Researches in Asia Minor, Pontus, and Armenia; with Some Account of their Antiquities and Geology. I. cilt. London: Printed by William Clowes and Sons, 1842.

Hawley, Walter A. Asia Minor. New York: Printed by William Brendon and Son LTD., 1918.

Kinneir, John Macdonald. Journey Througe Asia Minor, Armenia, and Koordistan, in the Years 1813 and 1814; with Remarks on the Marches of Alexander, and Retreat of the Ten Thousand. London: Printed by John Murray, 1818. 
Krickl, Ernst. 1892 Lykia Günlüğü. Çeviren Z. Zühre İlkgelen, Filiz Dönmez Öztürk. İstanbul: Suna ve İnan Kıraç Vakfi-Arkeoloji ve Sanat Yayınları, 2005.

Lennep, Henry J. Van, Travels in Little-Known Parts of Asia Minor; with Illustrations of Biblical Literature and Researches in Archeology. Volume II. London: Printed by W. Clowes and Sons, 1870.

Lennep, Henry J. Van. Bible Lands: their Modern Customs and Manners Illustrative of Scripture. New York: Harper \& Brothers, Publishers, 1875.

Michaud, M. ve M. Poujoulat. Correspondance d'Orient 1830-1831. Tome I. Paris: Ducollet LibraireEduteur, 1833

Mursaloğlu, Şemsettin. Büyük Reyhanlı Türkmen Aşireti Tarihi. İzmir: Karınca Matbaacılık, 1984.

Percy, Earl. Highlands of Asiatic Turkey. London: Printed by Enbia Office, 1901.

Perrot, Georges ve Charles Chipiez. History of Art in Phrygia, Lydia, Caria and Lycia. London: Printed by Chapman and Hall Limited, 1892.

Sarre, Friedrich. Reise in Kleinasien (Sommer 1895) Forschungen Zur Seldjukischen Kunst und Geographie des Landes. Berlin: Druck Von Otto Elsner, 1896.

Sarre, Friedrich. Küçükasya Seyahati (1895 Yazı) Selçuklu Sanatı ve Ülkenin Coğrafyası Üzerine Araştırmalar. Çeviren Dârâ Çolakoğlu. İstanbul: Pera Turizm ve Ticaret A.Ş. Yayını, 1998.

Seiff, Julius. Reisen in der Asiatischen Türkei. Leipzig: J. C. Hinrichs’sche Buchhandlung, 1875.

Spratt, T. A. B. ve Edward Forbes. Travels in Lycia, Milyas, and the Cibyratis. Volume I. London: Printed by S. \& J. Bentley, Wilson and Fley, 1847.

Spratt, T. A. B. ve Edward Forbes. Milyas, Kibyratis ve Likya'da Yolculuklar. Çeviren Doğan Türker. I. cilt. Antalya: Suna-İnan Kıraç Akdeniz Medeniyetleri Araştırma Enstitüsü Yayını, 2008.

Tavernier, John Baptista. The Six Voyages of John Baptista Tavernier, a Noble Man of France Now Living, Through Turky into Persia and the East-Indies. London: Printed for R. L. and M. P., 1678.

Tavernier, Jean Baptiste. Tavernier Seyahatnamesi. Çeviren Teoman Tunçdoğan. İstanbul: Kitap Yayınevi, 2006.

Taylor, Bayard. The Lands of the Saracens; or, Pictures of Palestine, Asia Minor, Sicily and Spain. New York: Printer, Stereotyper and Electrotyper, Carton Building, 1859.

Texier, Charles, Küçük Asya Coğrafyası Tarihi ve Arkeolojisi. Çeviren Ali Suat. 1. cilt. Ankara: Enformasyon ve Dökümantasyon Hizmetleri Vakfi Yayını, 2002.

Texier, Charles, Küçük Asya Coğrafyası Tarihi ve Arkeolojisi. Çeviren Ali Suat. 2. cilt. Ankara: Enformasyon ve Dökümantasyon Hizmetleri Vakfi Yayını, 2002.

Tozer, Henry Fanshawe, Researches in the Highlands of Turkey Including Visit to Mounts Ida, Athos, Olympus, and Pelion, to the Mirdite Albanians, and Other Remote Tribes. Volume I. London: Printed by William Clowes and Sons, 1869. 


\section{EKLER}

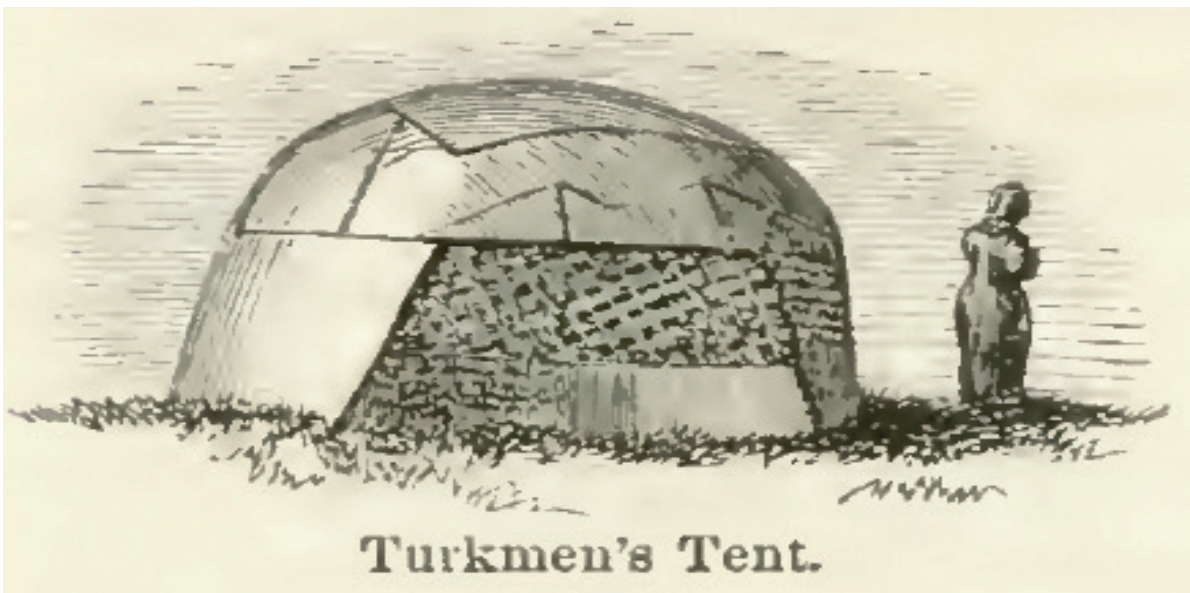

Resim 1: Topak Ev

Kaynak: Lennep, Bible Lands: Their Modern Customs and Manners Illustrative of Scripture, 400.

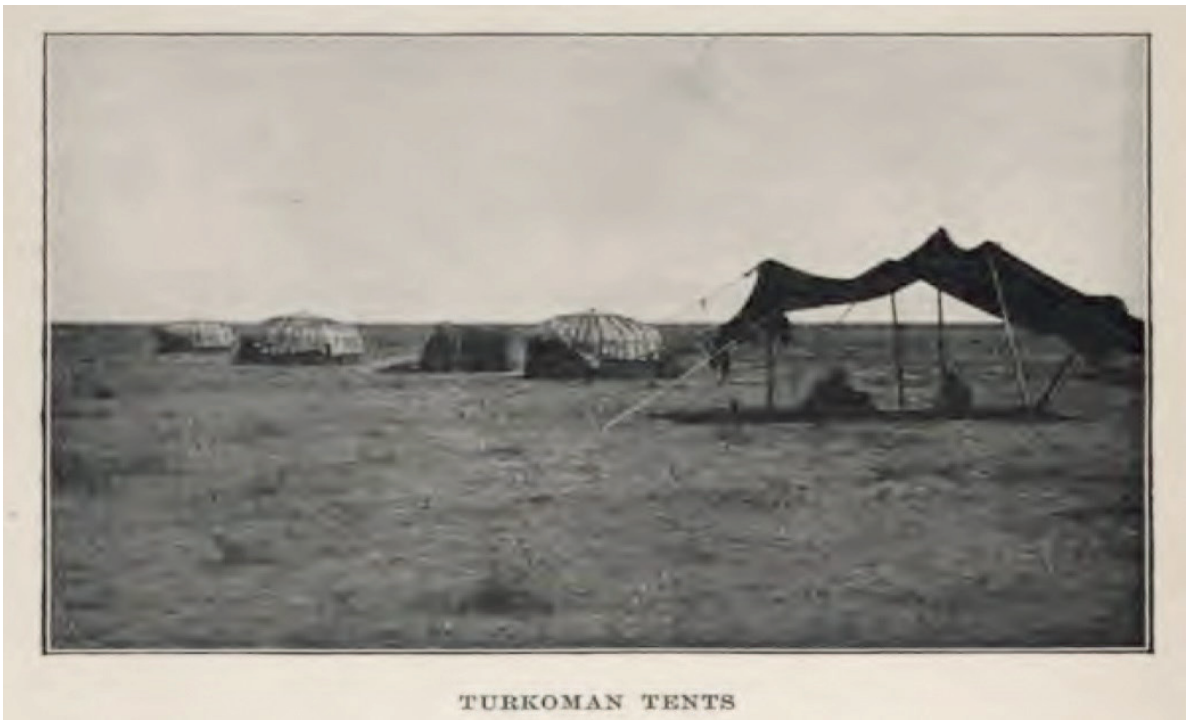

Resim 2: Topak Ev ve Karaçadır

Kaynak: Percy, Highlands of Asiatic Turkey, 50. 


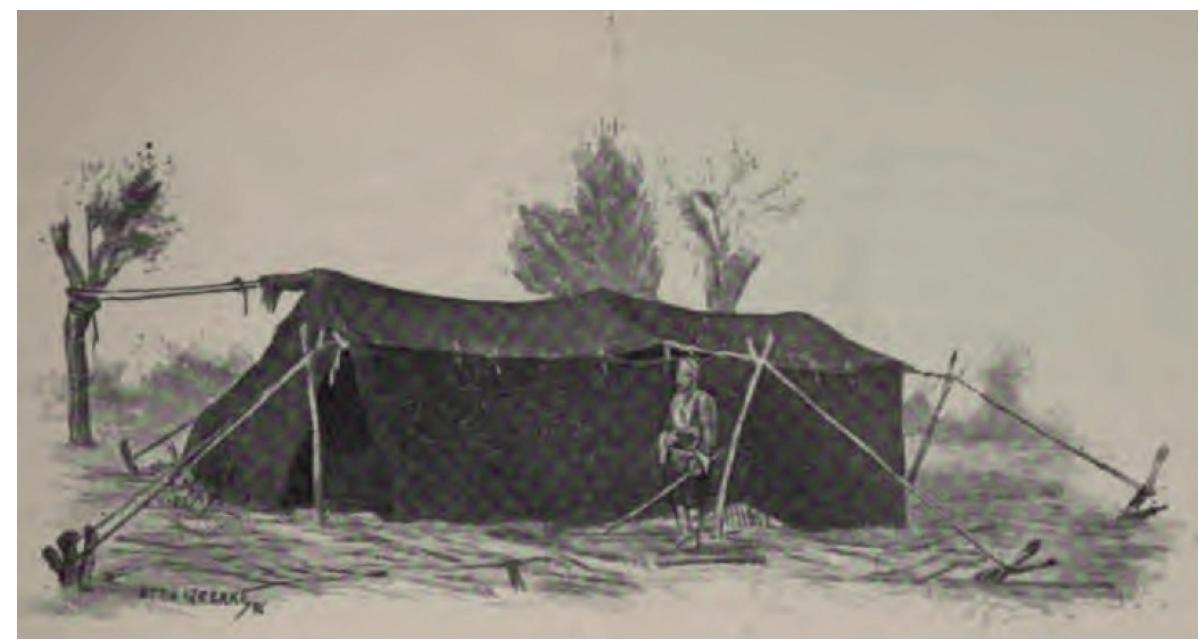

Resim 3: Karaçadır

Kaynak: Sarre, Reise in Kleinasien (Sommer 1895) Forschungen Zur Seldjukischen Kunst und Geographie des Landes, 107.

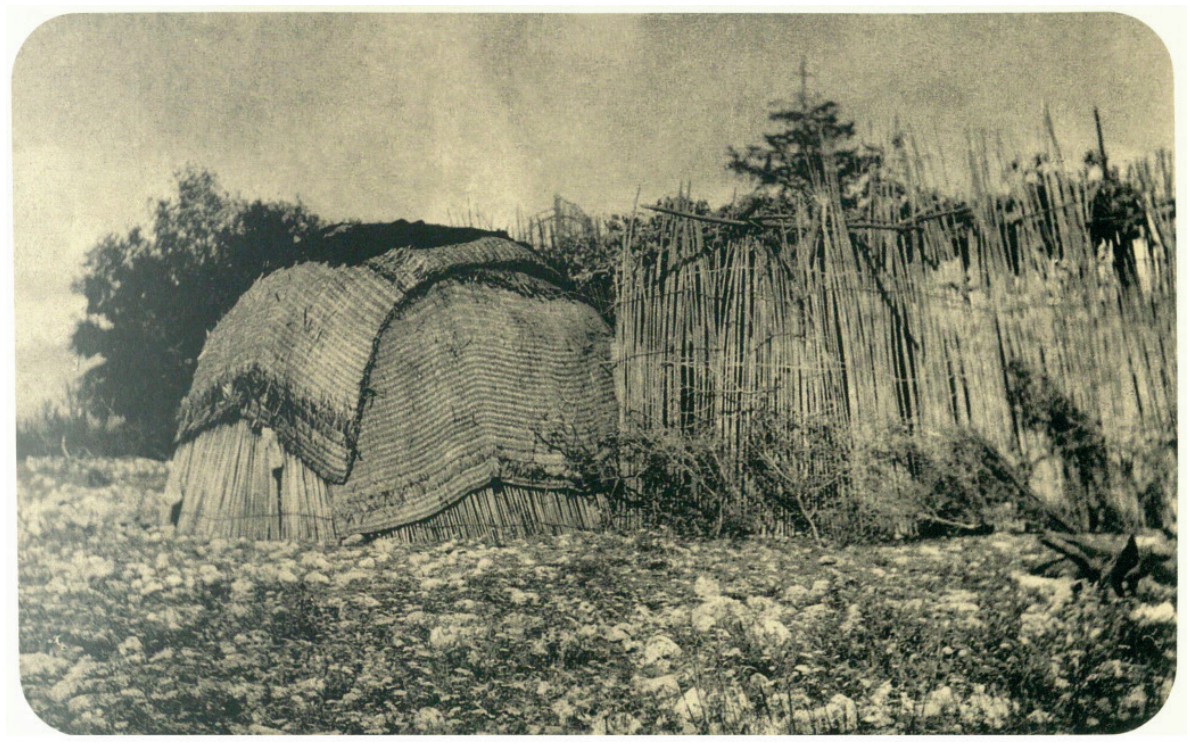

Resim 4: Alaçık

Kaynak: Krickl, 1892 Lykia Günlüğü, 142, 293. 


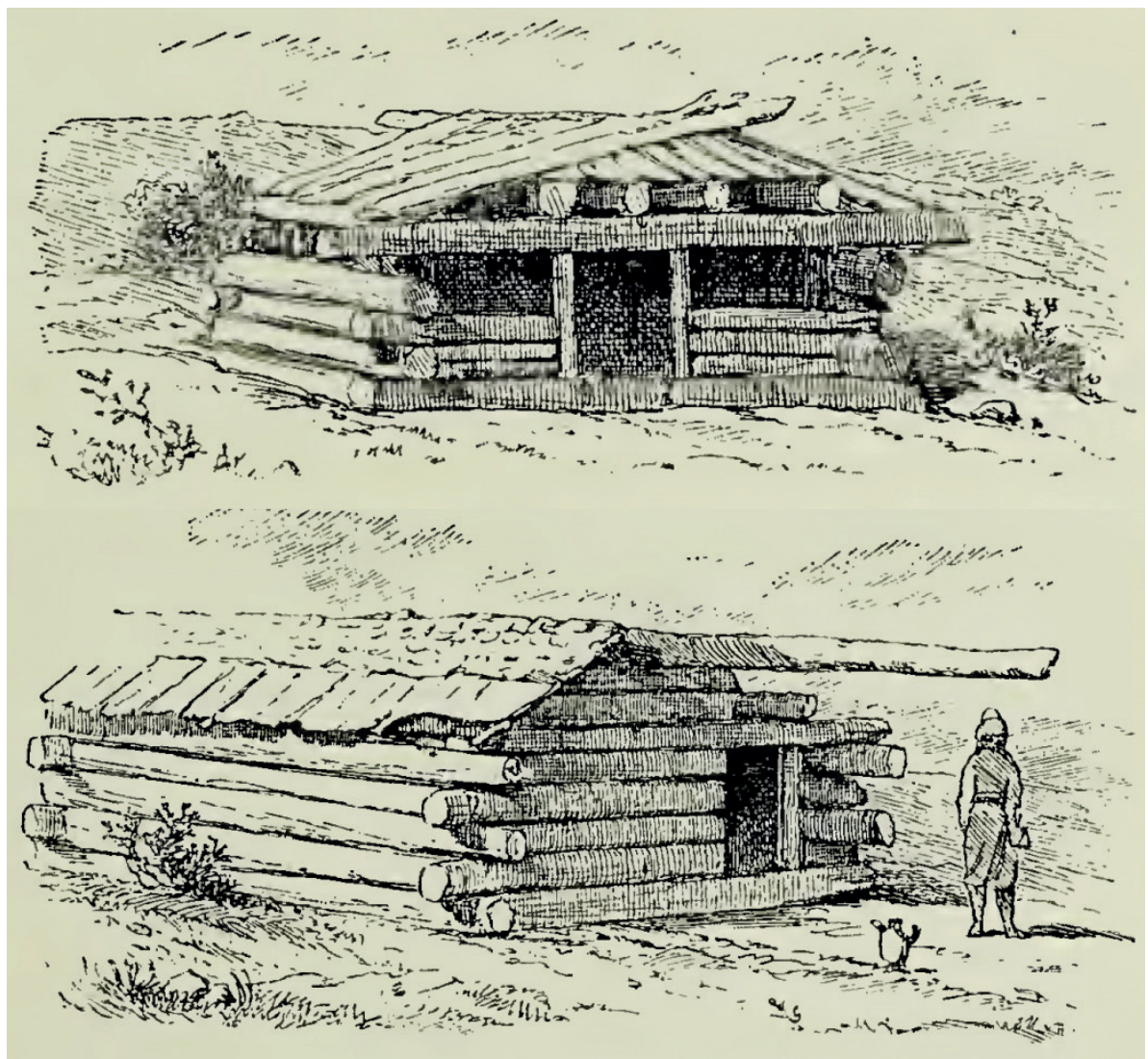

Resim 5: Ahşap Baraka

Kaynak: Perrot ve Chipiez, History of Art in Phrygia, Lydia, Caria and Lycia, 71. 
